\title{
Factors influencing physical functional status in intensive care unit survivors two years after discharge
}

\author{
Jaqueline S Haas ${ }^{1 *}$, Cassiano Teixeira², Claudia R Cabral ${ }^{3}$, Alessandra H D Fleig ${ }^{3}$, Ana Paula R Freitas ${ }^{3}$, \\ Erika C Treptow ${ }^{3}$, Márcia IB Rizzotto ${ }^{3}$, André S Machado ${ }^{4}$, Patrícia C Balzano ${ }^{4}$, Márcio P Hetzel3, \\ Daniele M Dallegrave ${ }^{3}$, Roselaine P Oliveira ${ }^{4}$, Augusto Savi ${ }^{4}$ and Silvia RR Vieira ${ }^{1}$
}

\begin{abstract}
Background: Studies suggest that in patients admitted to intensive care units (ICU), physical functional status (PFS) improves over time, but does not return to the same level as before ICU admission. The goal of this study was to assess physical functional status two years after discharge from an ICU and to determine factors influencing physical status in this population.
\end{abstract}

Methods: The study reviewed all patients admitted to two non-trauma ICUs during a one-year period and included patients with age $\geq 18 \mathrm{yrs}, \mathrm{ICU}$ stay $\geq 24 \mathrm{~h}$, and who were alive 24 months after ICU discharge. To assess PFS, Karnofsky Performance Status Scale scores and Lawton-Instrumental Activities of Daily Living (IADL) scores at ICU admission (K-ICU and L-ICU) were compared to the scores at the end of 24 months (K-24mo and L-24mo). Data at 24 months were obtained through telephone interviews.

Results: A total of 1,216 patients were eligible for the study. Twenty-four months after ICU discharge, 499 (41.6\%) were alive, agreed to answer the interview, and had all hospital data available. PFS (K-ICU: $86.6 \pm 13.8$ vs. K-24mo: $77.1 \pm 19.6, p<0.001)$ and IADL (L-ICU: $27.0 \pm 11.7$ vs. L-24mo: $22.5 \pm 11.5, p<0.001)$ declined in patients with medical and unplanned surgical admissions. Most strikingly, the level of dependency increased in neurological patients (K-ICU: $86 \pm 12$ vs. K-24mo: $64 \pm 21$, relative risk [RR] 2.6, 95\% Cl, 1.8-3.6, $\mathrm{p}<0.001$ ) and trauma patients (K-ICU: $99 \pm 2$ vs. K-24mo: $83 \pm 21, \mathrm{RR} 2.7,95 \% \mathrm{Cl}, 1.6-4.6, \mathrm{p}<0.001$ ). The largest reduction in the ability to perform ADL occurred in neurological patients (L-ICU: $27 \pm 7$ vs. L-24mo: $15 \pm 12, \mathrm{RR} 3.3,95 \% \mathrm{Cl}, 2.3-4.6 \mathrm{p}<0.001$ ), trauma patients (L-ICU: $32 \pm 0$ vs. L-24mo: $25 \pm 11$, RR 2.8, 95\% Cl, 1.5-5.1, $\mathrm{p}<0.001$ ), patients aged $\geq 65$ years (RR 1.4, $95 \% \mathrm{Cl}, 1.07-1.86, \mathrm{p}=0.01$ ) and those who received mechanical ventilation for $\geq 8$ days (RR $1.48,95 \% \mathrm{Cl}, 1.02-2.15$, $\mathrm{p}=0.03)$.

Conclusions: Twenty-four months after ICU discharge, PFS was significantly poorer in patients with neurological injury, trauma, age $\geq 65$ tears, and mechanical ventilation $\geq 8$ days. Future studies should focus on the relationship between PFS and health-related quality of life in this population.

Keywords: Activities of Daily Living, Physical Functional Status, Intensive Care Unit, Long-term Care, Mortality, Prognosis, Health-related Quality of Life

\footnotetext{
* Correspondence: jaque.haas@gmail.com

${ }^{1}$ Postgraduate Program in Medical Science, Medical School, Universidade Federal do Rio Grande do Sul (UFRGS), Porto Alegre, Brazil

Full list of author information is available at the end of the article
} 


\section{Background}

Intensive care unit (ICU) mortality has fallen dramatically since 1980 , at a yearly rate of $2.0 \%$. Such reduction can be attributed to changes in the delivery of critical care, including increased capacity, establishment of clinical networks and outreach services, implementation of ventilator care bundles [1], and enhancement of strategies to improve decision-making [2-4] and communication among staff, patients, and family members [3,5-7].

Nevertheless, ICU survivors are more susceptible to chronic illness [3,8-14] and increased long-term mortality [10-12,15-19]. The cumulative 12-month mortality of ICU survivors has been reported to range between $35 \%$ and $43 \%$ [20]. Five-year survival following ICU discharge is also lower in these patients when compared to populations matched by age $[10,11,19]$, pre-existing diseases [12], and sex [15,21]; physical function and quality of life may also be compromised as a result of critical illness. Therefore, in addition to short-term outcomes such as hospital mortality, other aspects must be investigated when dealing with life after ICU discharge [22,23].

The goal of this study was to assess physical functional status two years after discharge from an ICU and to determine factors influencing physical status in this population.

\section{Methods}

\section{Design}

This is a prospective cross-sectional cohort study. The medical records of two no-trauma ICUs were reviewed in search of adult patients with an ICU stay $\geq 24$ between December 1, 2005 and December 1, 2006. Twenty-four months after discharge, all survivors were contacted by phone. All living patients who agreed to participate were included in the study.

\section{Study population}

The study included patients from two ICUs: a 31-bed, closed ICU in a private hospital; and an 18-bed, open ICU

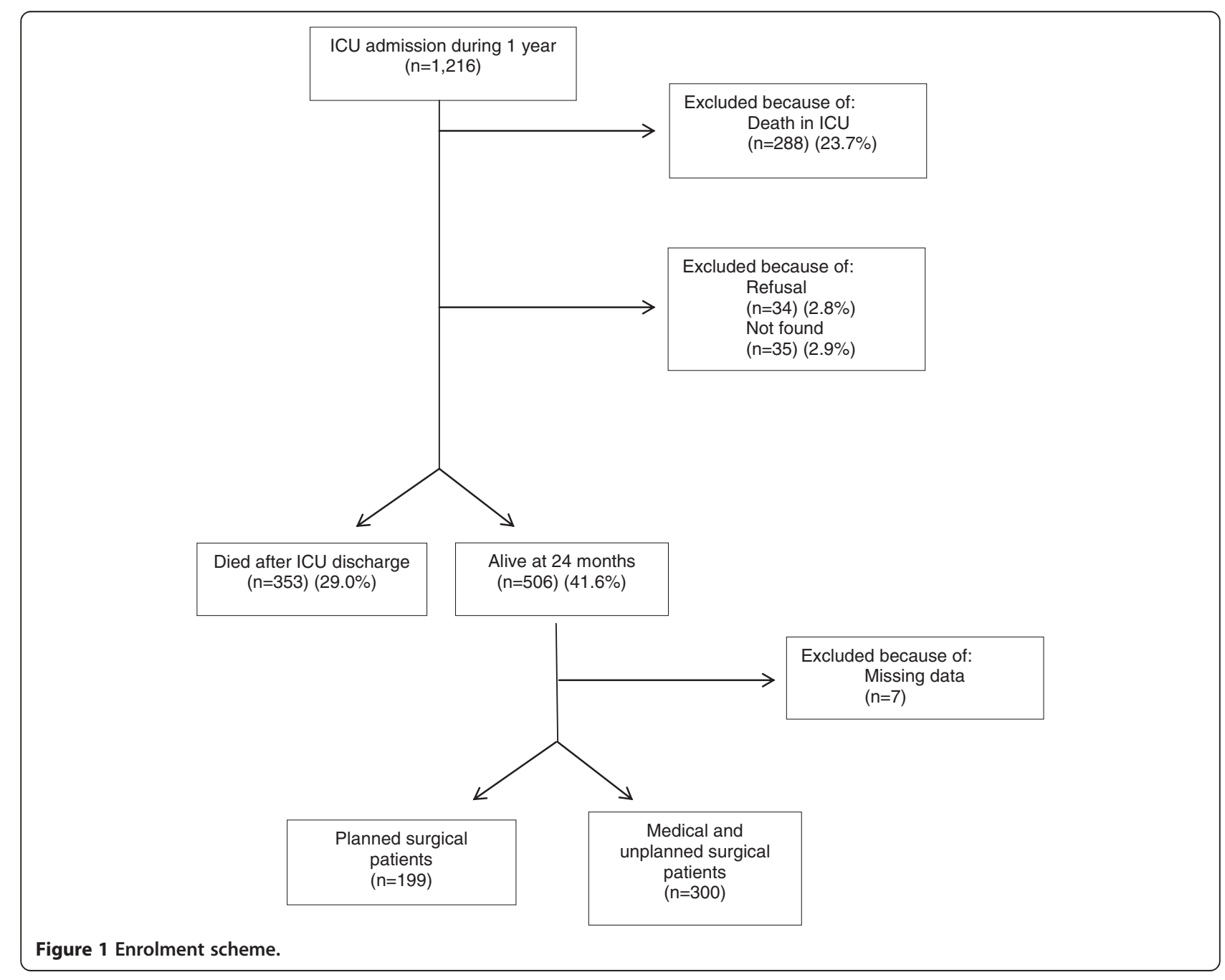


in a university hospital. Patients with ICU stay $<24$ hours were excluded. If the patient was readmitted to the ICU during the year in review, only data relating to the first admission were considered. The number of readmissions was measured only for sample characterization.

\section{Assessment of PFS}

PFS was assessed by the Karnofsky Performance Status Scale, which emphasizes physical performance and dependency. As a means to monitor the results obtained with the Karnosfky scale (since it is expected that poor physical status will entail decreased ability to perform ADLs), the Lawton-Instrumental Activities of Daily Living (IADL) Scale [23-26] was also applied. Karnofsky and Lawton scores were determined during ICU admission (K-ICU and L-ICU) and after 24 months (K-24mo and L-24mo).

\section{Data collection}

Daily records made by ICU physicians and fellows during the admission were reviewed. The following data were collected: baseline characteristics, age, gender, body mass index (BMI), pre-existing diseases, type of admission (medical, planned surgery or unplanned surgery), acute physiologic and chronic health evaluation (APACHE II) score at 1st ICU-day, and diagnosis on ICU admission. K-ICU score, L-ICU score, data on respiratory, cardiovascular, and dialysis treatments, diagnosis of sepsis, days on mechanical ventilation (MV), ICU-length of stay (LOS), sequential organ failure assessment (SOFA), and therapeutic intervention score (TISS) were also retrieved from the medical charts.

Two years after ICU discharge, patients were contacted via telephone. If the patient was unable to answer the telephone interview, the questions were answered by a proxy, if possible the same person providing information during the ICU admission. Proxies were defined as people with daily contact with the patient since before admission to the ICU.

The interviews were performed by one physician and six nurses. They were trained to use the study instruments and participated in a pilot study with 100 patients [6]. Periodic evaluations were performed to determine inter-rater reliability and to make sure that the quality of interviews remained similar/high among data collectors.

In addition to the Karnosfky and Lawton-IADL scales, the telephone interview focused on the patient's selfperception about their quality of life (a subjective question to test the reliability of the scales used).

\section{Data classification}

Changes in physical performance (K-ICU vs. K-24mo) and ability to perform daily activities (L-ICU vs. L-24mo) were categorized as: (a) functional improvement - increase in at least one of the scores over 24 months; (b) preserved functional status - no change in scores;

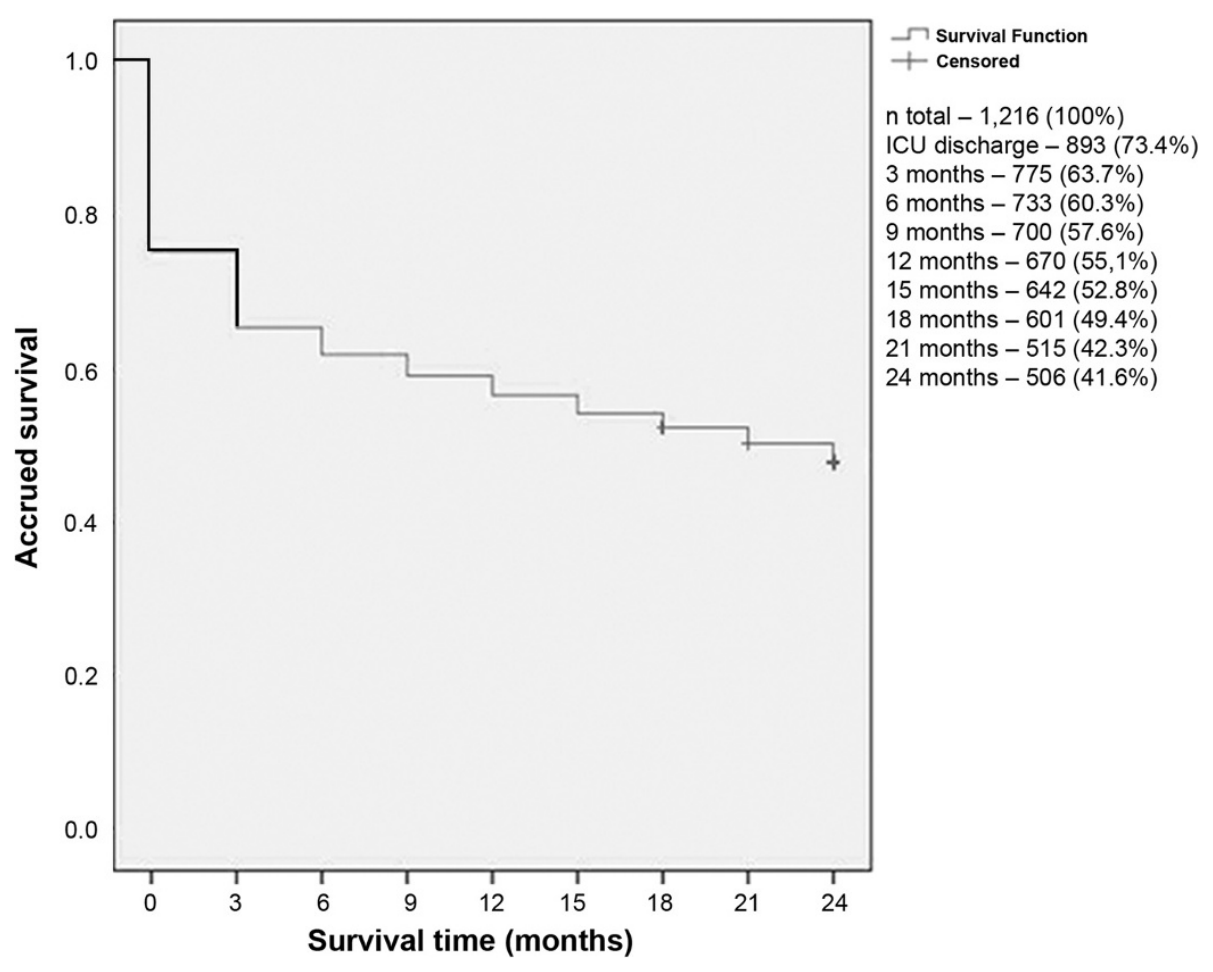

Figure 2 Kaplan-Meier survival curves. 
(c) moderate functional impairment - reduction of up to 29 points in $\mathrm{K}-24 \mathrm{mo}$ vs. K-ICU and reduction of up to 11 points in L-24mo vs. L-ICU; and (d) major functional impairment - reduction $\geq 30$ points in $\mathrm{K}-24 \mathrm{mo}$ vs. $\mathrm{K}-\mathrm{ICU}$, and $\geq 12$ points in L-24mo vs. L-ICU.

As a final question, patients were asked to rate their PFS at 24 months as compared to PFS during ICU-stay (worse, equal, or better).

\section{Ethics}

The study was approved by the ethics committees at Hospital Moinhos de Vento and Complexo Hospitalar da Santa Casa de Porto Alegre. Oral consent was provided at the start of the telephone interview.

\section{Statistical analysis}

Categorical variables were reported as percentages, and between-group comparisons were made by chi-square test. Continuous variables were reported as means \pm SD when variables were normally distributed or as medians and interquartile $\left[\mathrm{P}_{25}-\mathrm{P}_{75}\right]$ range when variables were not normally distributed. Differences between group means were compared by Student $t$ test for normally distributed variables. Chi-square tests or Fisher exact test were used to compare group medians for non-normally distributed variables.

A Kaplan-Meier curve was built to show patient survival. Adjusted residuals were used to evaluate associations between categorical variables and outcome. A paired Student $t$ test for quantitative variables was used to evaluate pre and post ICU scores. ANOVA followed by the Tukey test evaluated the association of APACHE II with four categories of the Karnofsky and LawtonADL indices. To examine the association of the SOFA score with the scale categories, the Kruskal-Wallis test was used, followed by the Tukey test. The analysis was adjusted for BMI, days on MV, type of ICU admission, age, pre-existing diseases, Glasgow coma score, and SOFA. In multivariate analyses, the predictors of functional status decline were expressed as relative risk (RR).

The analyses were performed with SPSS 16.0 software (SPSS Inc., Chicago, IL, USA), and level of significance was set at $p<0.05$.

\section{Results}

\section{Study population}

We identified 1,216 patients with $\mathrm{ICU}$ stay $\geq 48$ hours. Of these, 288 (23.7\%) died in the ICU. Phone calls were made to 928 ICU survivors. Thirty-five out of 1,216 patients (2.9\%) were not located (lost to follow-up), 34 (2.8\%) refused to participate, and 353 had died at the time the call was made: $733(60.3 \%)$ were alive after 6 months, 670 (55.1\%) after 12 months, and 601 (49.4\%) were alive after 18 months of admission. Five hundred
Table 1 Characteristics of ICU survivors two years after discharge

\begin{tabular}{|c|c|c|c|}
\hline ICU admission data & $\begin{array}{l}\text { Planned surgical } \\
\text { admission } \\
(n=199)\end{array}$ & $\begin{array}{c}\text { Medical and } \\
\text { unplanned } \\
\text { surgical admission } \\
(n=300)\end{array}$ & $p$ \\
\hline Age, years & $58.5 \pm 18.5$ & $62.4 \pm 17.0$ & 0.01 \\
\hline Male gender & $108(54.3)$ & $149(49.7)$ & ns \\
\hline \multicolumn{4}{|l|}{$\begin{array}{l}\text { Number of pre-existing } \\
\text { disorders }\end{array}$} \\
\hline$\leq 2$ & $176(88.5)$ & $244(81.3)$ & ns \\
\hline$>2$ & $23(11.5)$ & $56(18.7)$ & ns \\
\hline \multicolumn{4}{|l|}{$\mathrm{BMI}^{a}$} \\
\hline$<25 \mathrm{~kg} / \mathrm{m}^{2}$ & $81(40.7)$ & $121(40.3)$ & ns \\
\hline$\geq 25 \mathrm{Kg} / \mathrm{m}^{2}$ & $118(59.3)$ & $179(59.7)$ & ns \\
\hline $\begin{array}{l}\text { Reason for ICU- } \\
\text { admission }\end{array}$ & & & ns \\
\hline Planned surgery & 199 & - & \\
\hline Heart & - & $113(37.7)$ & \\
\hline Neurological & - & $59(19.7)$ & \\
\hline Respiratory & - & $60(20.0)$ & \\
\hline Trauma & - & $18(6.0)$ & \\
\hline Other & - & $50(16.6)$ & \\
\hline
\end{tabular}

Days on MV

Did not receive MV

$\begin{array}{cc}121(60.8) & 222(74.0) \\ 18(9.1) & 59(19.7) \\ 31(15.6) & 10(3.3) \\ 29(14.5) & 9(3.0) \\ 5[3: 8] & 6[3: 11]\end{array}$

Severity scores

APACHE II at 1st ICU

$10.2 \pm 5.4$

$14.2 \pm 8.2$

$<0.001$ day

SOFA at 1st ICU day

TISS at 1 st ICU day

0

$18 \pm 6.5$

[0:1]

ns

TISS at 3rd ICU day

$20.4 \pm 6.4$

$17.6 \pm 6.8$

0.06

TISS discharge

$11.5 \pm 3.7$

$17.4 \pm 6.8$

0.02

Evaluation of functional status at ICU admission

\section{Karnofsky scale (K-ICU)}

$87.8 \pm 10.5$

$86.6 \pm 13.8$

ns

Lawton scale (L-ICU)

$28.8 \pm 6.9$

$27.3 \pm 8.6$

ns

Evaluation of functional status after $24 \mathrm{mo}$

Karnofsky scale

(K-24mo)

Lawton scale (L-24mo)

$86.0 \pm 13.6$

$77.1 \pm 19.6$

$<0.001$

Data are number $(\%)$, mean \pm standard deviation or median $\left[\mathrm{P}_{25}: \mathrm{P}_{75}\right]$. APACHE II Acute Physiologic and Chronic Health Evaluation, BMI Body mass index, ICU Intensive Care Unit, LOS Length Of Stay, MV Mechanical Ventilation, SOFA Sequential Organ Failure Assessment, TISS Therapeutic Intervention Scoring System. 
and six patients (41.6\%) entered the study (Figure 1 and Figure 2). Hospital data were missing in 7 patients and therefore the results refer to 499 patients with complete hospital records who agreed to participate.

One hundred and eighty-five interviews were answered by the patients themselves, and 314 interviews were answered by proxies (179 [57\%] were sons and daughters, 88 [28\%] were spouses, and 47 [15\%] were caregivers). The ICU and 24-month interviews were answered by the same person in $318(63 \%)$ cases. Therefore, in 181 admissions, the person providing information in the ICU was not the same as the person providing information at 24 months.

The clinical characteristics of the population interviewed 24 months after ICU discharge were as follows: mean APACHE II score of $12.5 \pm 7.4$, planned surgery (39.9\%) as the most frequent type of ICU admission, and predominance of males (51.2\%). Differences between patients with planned surgical ICU admission vs. medical plus unplanned surgical ICU admission are shown in Table 1.

\section{Determinants of physical functional status $\mathbf{2 4}$ months after ICU discharge2}

Both Karnofsky and Lawton scores declined in medical and unplanned surgical patients admitted to the ICU 24 months after discharge (Figure 3B).

The greatest increase in the level of dependency was observed in neurological patients (K-ICU: $86 \pm 12$ vs. K-24mo: $64 \pm 21$, RR 2.6, 95\% CI, 1.8-3.6, $p<0.001)$ and trauma patients (K-ICU: $99 \pm 2$ vs. K-24mo: $83 \pm 21$, RR 2.7, 95\% CI, 1.6-4.6, $p<0.001$ ) (Table 2 and Table 3). The largest reduction in the ability to perform ADL occurred in neurological patients (L-ICU: $27 \pm 7$ vs. L-24mo: $15 \pm 12$, RR 3.3, 95\% CI, 2.3-4.6 $p<0.001$ ), trauma patients (L-ICU: $32 \pm 0$ vs. L-24mo: $25 \pm 11$,
RR 2.8, 95\% CI, 1.5-5.1, $p<0.001$ ), age $\geq 65$ years (RR $1.4,95 \% \mathrm{CI}, 1.07-1.86, p=0.01)$ and patients receiving MV for more than eight days (RR 1.48, 95\% CI, 1.02-2.15, $p=0.03$ ) (Table 2 and Table 3).

\section{Self-perception of physical functional status}

The decline in PFS subjectively perceived by patients was in agreement with the reduction in PFS indices measured. One hundred and fifty-six patients or proxies perceived functional status as worse than during the ICU admission. Of the patients who reported feeling worse, $83 \%(p<0.001)$ had moderate to severe functional impairment by Karnofsky index, and $76 \%(p<0.001)$ by Lawton-IADL index (Table 2).

\section{Discussion}

In the present study with ICU survivors interviewed 24 months after discharge, we observed a decline in physical functional status as measured by the Karnofsky and Lawton-IADL scales, especially in patients with neurological diagnoses or trauma, age $\geq 65$ years or 8 days or more on mechanical ventilation.

Nearly all patients with chronic critical illness leave the hospital with profound impairment of physical function, cognitive status, or both, requiring institutional care $[27,28]$. A systematic review of the literature showed that functional impairment is closely associated with age and disease severity [29]. After ICU discharge, elderly patients have been observed to require more assistance than younger counterparts to perform tasks such as using public transportation, shopping, and doing the laundry $[3,30]$. Our study confirmed this loss of ability to perform independently in patients aged $\geq 65$ years.

Conversely, whereas elderly patients often had good PFS or perceived their PSF as better than before critical illness, trauma patients, who were usually healthy and

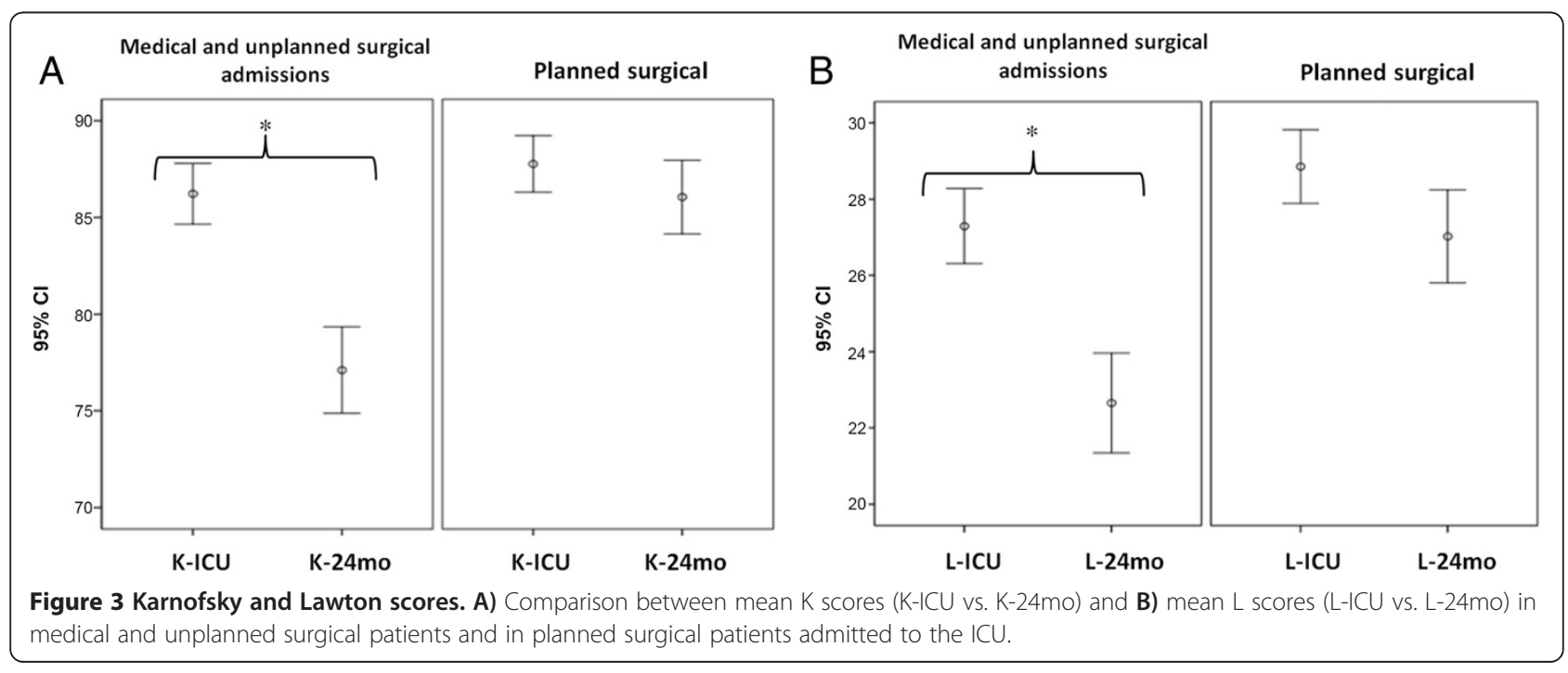


Table 2 Percentage of medical and unplanned surgical patients who had their ability to perform activities of daily life affected after ICU admission according to the Karnofsky and Lawton-instrumental activities of daily living scales

\begin{tabular}{|c|c|c|c|c|c|c|}
\hline \multirow[t]{2}{*}{ Variables } & \multirow[t]{2}{*}{$\mathbf{n}$} & \multicolumn{4}{|c|}{ Functional impairment (\%) } & \multirow[t]{2}{*}{$p$} \\
\hline & & Severe & Moderate & No change & Improvement & \\
\hline Age (Karnofsky), years & & & & & & $<0.001$ \\
\hline$<65$ & 265 & 7 & 26 & 53 & $14^{a}$ & \\
\hline$\geq 65$ & 234 & $13^{a}$ & 24 & 61 & 2 & \\
\hline Age (Lawton) & & & & & & $<0.001$ \\
\hline$<65$ & 265 & 12 & 14 & $66^{\mathrm{a}}$ & $8^{a}$ & \\
\hline$\geq 65$ & 234 & $20^{a}$ & $23^{\mathrm{a}}$ & 57 & 0 & \\
\hline Stay in ICU (Karnofsky) & & & & & & $<0.001$ \\
\hline$<7$ days & 401 & 7 & 24 & $59^{a}$ & $10^{a}$ & \\
\hline 8-14 days & 52 & $23^{a}$ & 29 & 48 & 0 & \\
\hline$\geq 15$ days & 46 & $23^{a}$ & 30 & 42 & 5 & \\
\hline \multicolumn{7}{|l|}{ Stay in ICU (Lawton) } \\
\hline$<7$ days & 401 & 13 & 17 & $65^{\mathrm{a}}$ & 5 & \\
\hline 8-14 days & 52 & 21 & 25 & 54 & 0 & \\
\hline$\geq 15$ days & 46 & $35^{\mathrm{a}}$ & 16 & 40 & 9 & \\
\hline $\mathrm{BMI}^{a}$ (Karnofsky) & & & & & & $<0.001$ \\
\hline$<25 \mathrm{Kg} / \mathrm{m}^{2}$ & 202 & 11 & 26 & 58 & 5 & \\
\hline$\geq 25 \mathrm{Kg} / \mathrm{m}^{2}$ & 297 & 4 & 21 & 51 & $24^{a}$ & \\
\hline $\mathrm{BMI}^{a}$ (Lawton) & & & & & & $<0.001$ \\
\hline$<30 \mathrm{Kg} / \mathrm{m}^{2}$ & 202 & 17 & 18 & 63 & 2 & \\
\hline$\geq 30 \mathrm{Kg} / \mathrm{m}^{2}$ & 297 & 10 & 18 & 55 & $17^{\mathrm{a}}$ & \\
\hline Reason for ICU admission (Karnofsky) & & & & & & $<0.001$ \\
\hline Heart & 113 & 5 & 22 & $69^{a}$ & 4 & \\
\hline Neurological & 59 & $39^{a}$ & 34 & 27 & 0 & \\
\hline Respiratory & 60 & 8 & 23 & $69^{a}$ & 0 & \\
\hline Trauma & 18 & 22 & $45^{a}$ & 33 & 0 & \\
\hline Planned surgery & 199 & 3 & 21 & 57 & $19^{a}$ & \\
\hline Other & 50 & 12 & 30 & 54 & 4 & \\
\hline Reason for ICU admission (Lawton) & & & & & & $<0.001$ \\
\hline Heart & 113 & 11 & 13 & $73^{\mathrm{a}}$ & 3 & \\
\hline Neurological & 59 & $51^{\mathrm{a}}$ & $30^{\mathrm{a}}$ & 17 & 2 & \\
\hline Respiratory & 60 & 8 & 20 & 70 & 2 & \\
\hline Trauma & 18 & 33 & 17 & 50 & 0 & \\
\hline Planned surgery & 199 & 8 & 18 & 66 & $8^{\mathrm{a}}$ & \\
\hline Other & 50 & 20 & 14 & 62 & 4 & \\
\hline Days on MV (Karnofsky) & & & & & & $<0.001$ \\
\hline Did not use MV & 352 & 9 & $27^{a}$ & 55 & 9 & \\
\hline 1 day & 78 & 5 & 17 & 67 & 11 & \\
\hline 2 to 7 days & 37 & 13 & 16 & 68 & 3 & \\
\hline$\geq 8$ days & 32 & $31^{a}$ & 25 & 44 & 0 & \\
\hline Days on MV (Lawton) & & & & & & 0.021 \\
\hline Did not use MV & 352 & 15 & 19 & 61 & 5 & \\
\hline
\end{tabular}


Table 2 Percentage of medical and unplanned surgical patients who had their ability to perform activities of daily life affected after ICU admission according to the Karnofsky and Lawton-instrumental activities of daily living scales (Continued)

\begin{tabular}{|c|c|c|c|c|c|c|}
\hline$\overline{1 \text { day }}$ & 78 & 10 & 12 & $73^{a}$ & 5 & \\
\hline 2 to 7 days & 37 & 19 & 13 & 65 & 3 & \\
\hline$\geq 8$ days & 32 & $33^{a}$ & 26 & 38 & 3 & \\
\hline APACHE $\|$ at 1 st ICU day & 499 & $14 \pm 6^{\S}$ & $12 \pm 6.5^{\S^{*}}$ & $13 \pm 8^{\S}$ & $8 \pm 5^{*}$ & $0.02^{*}$ \\
\hline SOFA at 1 st ICU day & 499 & $(0 \quad 0: 2)^{\S}$ & $(00: 1)^{\S^{*}}$ & $\left(\begin{array}{lll}0 & 0: 0\end{array}\right)^{*}$ & $(0 \quad 0: 0)^{*}$ & $0.003^{b}$ \\
\hline Subjective impression (Karnofsky) & & & & & & $<0.001$ \\
\hline Equal & 172 & 1 & 17 & $78^{a}$ & 4 & \\
\hline Worse & 156 & $30^{a}$ & $53^{a}$ & 17 & 0 & \\
\hline Better & 171 & 0 & 7 & $72^{a}$ & $21^{a}$ & \\
\hline Subjective impression (Lawton) & & & & & & $<0.001$ \\
\hline Equal & 172 & 4 & 14 & $82^{a}$ & 0 & \\
\hline Worse & 156 & $46^{a}$ & $30^{\mathrm{a}}$ & 24 & 0 & \\
\hline Better & 171 & 1 & 11 & $75^{\mathrm{a}}$ & $12^{\mathrm{a}}$ & \\
\hline
\end{tabular}

${ }^{a}$ Adjusted residuals > 1.96;

${ }^{b} p$ value according to Kruskal-Wallis;

$\S,{ }^{*}$ Equal symbols indicate absence of statistically significant difference according to Tukey test.

APACHE II Acute Physiologic and Chronic Health Evaluation, BMI Body Mass Index, ICU Intensive Care Unit, MV Mechanical ventilation, SOFA Sequential Organ

Failure Assessment.

young before ICU admission [23], may experience a substantial decline in PFS after the trauma, both in physical and psychosocial dimensions [31]. Delusional memories, depression [32], and the inability to return to work negatively [33] influenced their perceived quality of life. Our study confirmed that trauma decreases the ability to perform activities independently by 2.8 times, and increases the level of dependency by 2.7 times.

The need for prolonged intensive care may also affect prognosis in terms of the ability to perform ADL [34]; previous articles $[35,36]$ have reported that the inability to independently perform activities of daily living is a major factor affecting health-related quality of life (HRQoL) in ICU survivors. In that sense, prolonged MV

Table 3 Probability of decrease in physical functional score 24 months after ICU discharge

\begin{tabular}{lccc}
\hline Characteristic & RR & $\mathbf{9 5 \% ~ C l}$ & $\boldsymbol{p}$ \\
\hline Reason for ICU admission & & & \\
Medical and unplanned & 1.3 & $1.1-1.5$ & 0.04 \\
$\begin{array}{l}\text { surgery (Karnofsky) } \\
\text { Medical and unplanned }\end{array}$ & 1.3 & $1.01-1.65$ & 0.03 \\
surgery (Lawton-ADL) & & & \\
Neurological (Karnofsky) & 2.6 & $1.8-3.6$ & $<0.001$ \\
Neurological (Lawton-ADL) & 3.3 & $2.3-4.6$ & $<0.001$ \\
Trauma (Karnofsky) & 2.7 & $1.6-4.6$ & $<0.001$ \\
Trauma (Lawton-ADL) & 2.8 & $1.5-5.1$ & 0.001 \\
Age $\geq 65$ years (Lawton-ADL) & 1.4 & $1.07-1.86$ & 0.01 \\
MV $\geq 8$ days (Lawton-ADL) & 1.48 & $1.02-2.15$ & 0.03 \\
\hline
\end{tabular}

ICU Intensive Care Unit, MV Mechanical Ventilation, RR Relative Risk. appears to reduce life quality and expectancy in the long term $[34,37,38]$. Our study demonstrated that the use of MV for 8 or more days reduced the ability to perform ADL by 1.48 times. According to some authors, $5 \%$ to $20 \%$ of ICU patients receive $\mathrm{MV}$, and $25 \%$ require MV for more than seven days [39]. In our study, $29.5 \%$ required MV and $21.8 \%$ of these received ventilatory support for more than eight days.

In our paper, patients with medical and unplanned surgical admissions had decreased PFS; however, this finding did not necessarily imply a reduction in the patients' actual ability to perform ADLs. Orwelius et al. $[40,41]$ suggested that pre-existing disease is the most important factor for long-term HRQoL after critical illness, and not the factors related to ICU-stay. This was not true for our patients, in whom the presence of pre-existing disease had less impact on PFS than prolonged MV and type of ICU admission (neurological and trauma patients).

Many studies refer to quality of life instead of functional status. HRQoL is a broad concept, which encompasses the ability to perform ADL [24]. In this study, two scales were used in the assessment of PFS, so as to increase the reliability of our results. The Karnofsky index (emphasizing the physical performance and dependency) was chosen because it covers more general aspects of the ability to perform ADL and because it is easy to interpret. Functional impairment has a direct impact on HRQoL because it limits autonomy and physical and mental abilities [13]. Future studies should also address other issues in relation to PFS, such as cognitive impairment, sleep disturbances, post-traumatic stress 
disorder, the rehabilitation process, employment status, and cultural and payment differences, can influence quality of life in a less tangible way than, for example, physical impairments after major trauma.

Studies assessing HRQoL after ICU suggest that ICU patients do not return to the same level of health that they had before they fell ill $[23,29]$, and that their HRQoL is lower than that of the general population, at least in the early years $[3,9,13,15,17,18,20]$. According to Oeyen et al. [23], a follow-up of 12 or 24 months is probably the best to capture changes that have a negative impact quality of life after intensive care.

The strengths of present study include a large sample $(\mathrm{n}=499)$, the fact that possible seasonal variations were accounted for (all admissions in one-year), and a long follow-up period (two-years), in addition to the combined use of two scales to increase the reliability of results and a low rate of individuals lost to follow-up (2.9\%). However, some limitations must also be addressed: (a) the interviews were conducted by phone and not faceto-face with the patients. However, 26 of the 53 authors cited by Oeyen et al. [23] also conducted telephone interviews; (b) only physical functional status, and not HRQoL, was measured; (c) the fact that some interviews were answered by proxies. However, the literature varies concerning the effect of using proxies. Some authors suggest that proxies (next-of-kin) may underestimate quality of life in their relatives [18,23]; (d) finally, the present population included many patients with cardiovascular problems and elective surgery, that is, a group of not very sick patients that may not reflect the usual critical care group of patients. Therefore, the present results may not allow generalization.

\section{Conclusions}

Twenty-four months after ICU discharge, PFS was significantly poorer in patients with neurological injury, trauma, age $\geq 65$ tears, and mechanical ventilation $>8$ days. Future studies should also focus on the relationship between PFS and HRQoL in this population.

\section{Abbreviations \\ ADL: Activity daily living; APACHE: Acute physiological and chronic health evaluation; ARDS: Acute respiratory distress syndrome; ATS: American thoracic society; BMl: Body mass index; COPD: Chronic obstructive pulmonary disease; K: Karnofsky index; GOS: Glasgow outcome score; HRQOL: Heath-related quality of life; ICU: Intensive care medicine; L: Lawton index; LOS: Length of stay; MV: Mechanical ventilation; NYHA New York Heart Association; PFS: Physical functional status; RR: Relative risk; SOFA: Sequential organ failure assessment; TISS: Therapeutic intervention scoring system.}

\section{Competing interests}

The authors declare that they have no competing interests.

\section{Authors' contributions}

JS Haas and C Teixeira reviewed the literature and wrote the manuscript. JS Haas, C Teixeira, CR Cabral, AHD Fleig, APR Freitas, EC Treptow, and MIB
Rizzotto conducted the telephone interview. AS Machado, MP Hetzel, DM Dallegrave, PC Balzano, and RP Oliveira collected the data base of ICU. A Savi and SRR Vieira significantly contributed for the manuscript. JS Haas performed the statistical analysis. JS Haas and C Teixeira assure the accuracy of the presented data. All authors have read and approved the final manuscript.

\section{Acknowledgements}

The authors would like to thank the Universidade Federal do Rio Grande do Sul (UFRGS), Universidade Federal de Ciências da Saúde de Porto Alegre (UFCSPA), Hospital Moinhos de Vento (HMV), and Complexo Hospitalar da Santa Casa (ISCMPA), all in Porto Alegre, Brazil.

A special thanks to Dr. Nilton Brandão da Silva (HMV), and Jorge Amilton Hoher (ISCMPA), who allowed and encouraged this study.

The study was carried at the Hospital Moinhos de Vento and at the Complexo Hospitalar da Santa Casa, Porto Alegre, Brazil.

\section{Author details}

${ }^{1}$ Postgraduate Program in Medical Science, Medical School, Universidade Federal do Rio Grande do Sul (UFRGS), Porto Alegre, Brazil. ${ }^{2}$ Medical School Universidade Federal de Ciências da Saúde de Porto Alegre (UFCSPA), Porto Alegre, Brazil. ${ }^{3}$ Department of Critical Care - Central-ICU of Complexo, Hospitalar da Santa Casa, Porto Alegre, Brazil. ${ }^{4}$ Department of Critical Care, Hospital Moinhos de Vento, Porto Alegre, Brazil.

Received: 3 March 2012 Accepted: 4 June 2013

Published: 18 June 2013

\section{References}

1. Hutchings A, Durand MA, Grieve R, Harrison D, Rowan K, Green J, Cairns J, Black N: Evaluation of modernisation of adult critical care services in England: time series and cost effectiveness analysis. BMJ 2009, 339:b4353.

2. Cook D, Rocker G, Marshall J, Griffith L, McDonald E, Guyatt G: Levels of care in the intensive care unit: a research program. Am J Crit Care 2006, 15:269-279.

3. Azoulay E, Pochard F, Kentish-Barnes N, Chevret S, Aboab J, Adrie C, Annane D, Bleichner G, Bollaert PE, Darmon M, et al: Risk of post-traumatic stress symptoms in family members of intensive care unit patients. Am J Respir Crit Care Med 2005, 171:987-994.

4. Tian J, Kaufman DA, Zarich S, Chan PS, Ong P, Amoateng-Adjepong Y, Manthous CA: Outcomes of critically ill patients who received cardiopulmonary resuscitation. Am J Respir Crit Care Med 2010, 182:501-506.

5. Reader TW, Flin R, Mearns $\mathrm{K}$, Cuthbertson $\mathrm{BH}$ : Interdisciplinary communication in the intensive care unit. Br J Anaesth 2007, 98:347-352.

6. Cabral CR, Teixeira C, De Oliveira RP, Hass JS, Azzolin KO: Mortality assessment and quality of life two years after discharge from the ICU: preliminary data from a prospective cohort. Rev Bras Ter Intensiva 2009, 21:18-24.

7. Teixeira C, Teixeira TML, Brodt SFM, Oliveira RP, Dexheimer Neto FL, Roehrig C, Oliveira ES: Appropriate medical professionals communication reduces intensive care unit mortality. Rev Bras Ter Intensiva 2010, 22:112-117.

8. Hennessy D, Juzwishin K, Yergens D, Noseworthy T, Doig C: Outcomes of elderly survivors of intensive care: a review of the literature. Chest 2005, 1764:1774.

9. Orme J Jr, Romney JS, Hopkins RO, Pope D, Chan KJ, Thomsen G, Crapo RO, Weaver LK: Pulmonary function and health-related quality of life in survivors of acute respiratory distress syndrome. Am J Respir Crit Care Med 2003, 167:690-694.

10. De Rooij SE, Abu-Hanna A, Levi M, De Jonge E: Factors that predict outcome of intensive care treatment in very elderly patients: a review. Crit Care 2005, 9:R307-R314.

11. Kaarlola A, Tallgren M, Pettila V: Long-term survival, quality of life, and quality-adjusted life-years among critically ill elderly patients. Crit Care Med 2006, 34:2120-2126

12. Rivera-Fernandez R, Navarrete-Navarro P, Fernandez-Mondejar E, RodriguezElvira M, Guerrero-Lopez F, Vazquez-Mata G: Six-year mortality and quality of life in critically ill patients with chronic obstructive pulmonary disease. Crit Care Med 2006, 34:2317-2324

13. Desai SV, Law TJ, Needham DM: Long-term complications of critical care. Crit Care Med 2011, 39:371-379. 
14. Flaatten $\mathrm{H}$ : Mental and physical disorders after ICU discharge. Curr Opin Crit Care 2010, 16:510-515.

15. Fildissis G, Zidianakis V, Tsigou E, Koulenti D, Katostaras T, Economou A, Baltopoulos G: Quality of life outcome of critical care survivors eighteen months after discharge from intensive care. Croat Med J 2007, 48:814-821.

16. Bagshaw SM, Mortis G, Doig CJ, Godinez-Luna T, Fick GH, Laupland KB: One-year mortality in critically ill patients by severity of kidney dysfunction: a population-based assessment. Am J Kidney Dis 2006, 48:402-409.

17. Cuthbertson BH, Hull A, Strachan M, Scott J: Post-traumatic stress disorder after critical illness requiring general intensive care. Intensive Care Med 2004, 30:450-455.

18. Cuthbertson BH, Roughton S, Jenkinson D, Maclennan G, Vale L: Quality of life in the five years after intensive care: a cohort study. Crit Care 2010, 14:R6.

19. Hamel MB, Davis RB, Teno JM, Knaus WA, Lynn J, Harrell F Jr, Galanos AN, Wu AW, Phillips RS: Older age, aggressiveness of care, and survival for seriously ill, hospitalized adults. SUPPORT Investigators. Study to Understand Prognoses and Preferences for Outcomes and Risks of Treatments. Ann Intern Med 1999, 131:721-728.

20. Eddleston JM, White P, Guthrie E: Survival, morbidity, and quality of life after discharge from intensive care. Crit Care Med 2000, 28:2293-2299.

21. Wright JC, Plenderleith L, Ridley SA: Long-term survival following intensive care: subgroup analysis and comparison with the general population. Anaesthesia 2003, 58:637-642.

22. Angus DC, Carlet J: Surviving intensive care: a report from the 2002 Brussels Roundtable. Intensive Care Med 2003, 29:368-377.

23. Oeyen SG, Vandijck DM, Benoit DD, Annemans L, Decruyenaere JM: Quality of life after intensive care: a systematic review of the literature. Crit Care Med 2010, 38:2386-2400.

24. Hayes JA, Black NA, Jenkinson C, Young JD, Rowan KM, Daly K, Ridley S: Outcome measures for adult critical care: a systematic review. Health Technol Assess 2000, 4:1-111.

25. Karnofsky DA, Abelmann WH, Craver LF, Burchenal JH: The use of nitrogen mustards in the palliative treatment of carcinoma. Cancer 1948, 1:634-656.

26. Lawton M, Brody E: Assessment of older people: self-maintaining and instrumental activities of daily living. Gerontologist 1969, 9:179-186.

27. Carson SS, Bach PB, Brzozowski L, Leff A: Outcomes after long-term acute care. An analysis of 133 mechanically ventilated patients. Am J Respir Crit Care Med 1999, 159:1568-1573.

28. Rimachi R, Vincent JL, Brimioulle S: Survival and quality of life after prolonged intensive care unit stay. Anaesth Intensive Care 2007, 35:62-67.

29. Dowdy DW, Eid MP, Sedrakyan A, Mendez-Tellez PA, Pronovost PJ, Herridge MS, Needham DM: Quality of life in adult survivors of critical illness: a systematic review of the literature. Intensive Care Med 2005, 31:611-620.

30. Vest MT, Murphy TE, Araujo KL, Pisani MA: Disability in activities of daily living, depression, and quality of life among older medical ICU survivors: a prospective cohort study. Health Qual Life Outcomes 2011, 9:9.

31. Vles WJ, Steyerberg EW, Essink-Bot ML, Van Beeck EF, Meeuwis JD, Leenen $L P$ : Prevalence and determinants of disabilities and return to work after major trauma. J Trauma 2005, 58:126-135.

32. Bombardier CH, Fann JR, Temkin NR, Esselman PC, Barber J, Dikmen SS: Rates of major depressive disorder and clinical outcomes following traumatic brain injury. JAMA 2010, 303:1938-1945.

33. Ulvik A, Kvale R, Wentzel-Larsen T, Flaatten H: Quality of life 2-7 years after major trauma. Acta Anaesthesio/ Scand 2008, 52:195-201.

34. Combes A, Costa MA, Trouillet JL, Baudot J, Mokhtari M, Gibert C, Chastre J: Morbidity, mortality, and quality-of-life outcomes of patients requiring > or $=14$ days of mechanical ventilation. Crit Care Med 2003, 31:1373-1381.

35. Andersen CK, Wittrup-Jensen KU, Lolk A, Andersen K, Kragh-Sorensen P: Ability to perform activities of daily living is the main factor affecting quality of life in patients with dementia. Health Qual Life Outcomes 2004, 2:52.

36. Herridge MS, Tansey CM, Matte A, Tomlinson G, Diaz-Granados N, Cooper A Guest CB, Mazer CD, Mehta S, Stewart TE, et al: Functional disability 5 years after acute respiratory distress syndrome. N Engl J Med 2011, 364:1293-1304.

37. Lipsett PA, Swoboda SM, Dickerson J, Ylitalo M, Gordon T, Breslow M, Campbell K, Dorman T, Pronovost P, Rosenfeld B: Survival and functional outcome after prolonged intensive care unit stay. Ann Surg 2000, 231:262-268.

38. Tonnelier A, Tonnelier JM, Nowak E, Gut-Gobert C, Prat G, Renault A, Boles JM, L'Her E: Clinical relevance of classification according to weaning difficulty. Respir Care 2011, 56:583-590.

39. Esteban A, Anzueto A, Frutos F, Alia I, Brochard L, Stewart TE, Benito S, Epstein SK, Apezteguia C, Nightingale P, et al: Characteristics and outcomes in adult patients receiving mechanical ventilation: a 28-day international study. JAMA 2002, 287:345-355.

40. Orwelius L, Nordlund A, Nordlund P, Edell-Gustafsson U, Sjoberg F: Prevalence of sleep disturbances and long-term reduced health-related quality of life after critical care: a prospective multicenter cohort study. Crit Care 2008, 12:R97.

41. Orwelius L, Nordlund A, Nordlund P, Simonsson E, Backman C, Samuelsson A, Sjoberg F: Pre-existing disease: the most important factor for health related quality of life long-term after critical illness: a prospective, longitudinal, multicentre trial. Crit Care 2010, 14:R67.

doi:10.1186/1471-2253-13-11

Cite this article as: Haas et al:: Factors influencing physical functional status in intensive care unit survivors two years after discharge. $B M C$ Anesthesiology 2013 13:11

\section{Submit your next manuscript to BioMed Central and take full advantage of:}

- Convenient online submission

- Thorough peer review

- No space constraints or color figure charges

- Immediate publication on acceptance

- Inclusion in PubMed, CAS, Scopus and Google Scholar

- Research which is freely available for redistribution

Submit your manuscript at www.biomedcentral.com/submit
C) Biomed Central 